\title{
The In-depth Exploitation and Three-dimensional Communication of Geological Cultural Resources
}

\author{
Dike Zhang ${ }^{1, *} \quad$ Shuying Xiao ${ }^{2}$ \\ China University of Geosciences, 430074, China ${ }^{1, *} \quad$ Huazhong Agricultural University, 430070, China ${ }^{2}$ \\ zdk715@126.com ${ }^{1, *}$
}

\begin{abstract}
The construction and development of geological culture, rational development and utilization of geological cultural resources, is of great importance for the prosperity of scientific and cultural undertakings. Geological culture is a resource embodying a great potential, which should be exploited in depth and spread in three-dimensional level. In the paper, the author clarifies the scientific connotation of geological culture resources, analyzes the prerequisites and approaches for in-depth exploitation, and finally emphasizes the importance of three-dimensional communication of geological cultural resources. Thus the constantly extensive geological cultural industry and industry group and chain can be formed; earth science knowledge and geological culture can be popularized in the world.
\end{abstract}

Keywords-Geological Culture Resources; Exploitation; Three-Dimensional Communication

\section{INTRODUCTION}

With the rapid development of economy, the contradiction between the earth and human-beings become prominent. Predatory development causes limitations of resources and environment damage, thus leading to the emergence of a global dilemma including abnormal climate, the greenhouse effect, the deterioration of ecological environment, vegetation degradation, desertification, water pollution and shortage and energy crisis. How to keep balanced development in economy, society, environment and the population? It has become a global challenge people have to face and resolve. In this context, the study of earth science and geological culture is particularly important.

Geological culture is a sub system of science and culture, and is an essential part of the advanced social culture. For many years, geoscientists have been talking about geological culture, pondering upon all the economical, social and cultural aspects that are essential in geological research and practice, because of the close link between earth science and human-beings. As is maintained, geology is a science, and as such it is culture, and therefore it can transfer cultural values to a society, as first of all the values in the world. The construction and development of geological culture mainly depends on proper exploitation of geological culture resources. Thus, rational exploitation and utilization of geological cultural resources is conducive to play the function of economy, education, culture and society, which will improve human beings' scientific and cultural quality, and also build a harmonious society between earth and human-beings.

\section{SCIENTIFIC CONNOTATION OF GEOLOGICAL Cultural Resources}

As the main object of earth science construction and research, geological culture resources are the important carrier and foundation of the earth science development, and occupy very important position in the allocation of culture resources in China. Geological culture resources provide the material foundation for the inheritance, innovation and development of earth science, and for the harmony between human and nature, so as to realize the sustainable development of human-beings. Until now there isn't a recognized conception of geoscience culture resources. As a kind of cultural resources, geological culture resources are an assembly of all kinds of natural resources and human resources, by using of which people are engaged in geological culture works, production of geological cultural product, industrialization of geological culture, popularization of earth science, and communication of geological culture.

The study of geological culture resources is closely related to earth science, which shed light on the study of geological culture resources. Earth science involves the close link and coordination of relationship between the earth and human-beings, emphasizes on people-oriented, and seek for system science of the sustainable development of the earth and human-beings. Research of earth science includes multi-discipline such as history, religion, cultural, economy etc. Earth science is a harmonious relationship between human and nature. It is an important scientific significance and social value to promote the sustainable development of human resources in the world. All of features above make reference on the research of geological culture resources, which have profound academic foundation and unique culture rationale, with abundant comprehensive resource materials, and have important scientific significance and social value in the sustainable social environment development.

\section{EXPLOITATION IN DEPTH OF GEOLOGICAL CULTURAL}

\section{RESOURCES}

As is acknowledged, earth science is a multi-disciplinary involving the history, religion, 
humanities, economic and other great disciplines, studying the earth, minerals, water, forests, oceans, ecology, environment, etc. Also, earth science boasts a long history from the ancient Stone Age to modern society. So the geological culture resources have complete and abundant resource materials, which have great potential to develop into a variety of products.

To develop geological culture resources, the point we should bear in mind is to gear to the needs of market and to integrate abundant resources. It is the inevitable trend to fully excavate the potential geological culture resources and exploit geological culture resources into geological product and service. Geological cultural resources can be classified into the visible geological culture resources such as landscapes and geological figures and intangible geological culture resources such as geological knowledge, geological disasters and geological history. Other than some geological culture resources with public welfare which cannot be used for commercial needs, a great many geological culture resources can in fact be processed and developed into the masses of cultural products, such as science and technology product, geological film and television works, science fiction stories, novel with geologist as protagonist, drama, creation animation works, etc.

\section{A. Prerequisites of Geological Cultural Resources Exploitation}

The exploitation of geological cultural resources is mainly the process of the industrialization as well as protection of geological cultural resources. As a special kind of capital, it is necessary to have the following prerequisites in order to transform into the geological cultural products and services:

Prerequisites 1: Geological cultural resources must be transformed into the material form of consumption.

Both visible and invisible geological culture resources must be transformed into audible, visual and physical form. Because only in this way can they enter the market circulation and be recognized by consumers. For example, geological folk resource is one kind of intangible geological cultural resources. If we develop them into a folk village and folk festival activities which consumer can experience, then they have the economic value.

Prerequisites 2: Geological cultural resources have market value.

Geological cultural resources with market value can be brought into market, and then they have the potential of industrial development. And conversely, those without market value or small value should be excluded from the industrial development. Generally speaking, the market value of geological cultural resources is determined by the quality of the resources. If they are unique and irreplaceable, the market value is higher, and vice versa.

Prerequisites 3: Geological cultural resources have clear property right.

Property right is the right of ownership, including ownership and management. In the development and investment of resource industry, we should uphold the principle that those who invests will benefit and also take risk. If the property right relationship, investment and development will not be normal. Clear ownership of property rights is a prerequisite for the development of geological resources industry.

Prerequisites 4: Investment of geological cultural resources has appreciation in return.

Appreciation of investment value is the essential condition for the development of the geological cultural resources. The so-called industrial development and investment in the geological cultural resources is to make the necessary economic investment in order to get high cost of profit and return on investment. One thing should to mention, return on investment is mainly on economic benefits, but not all on economic profits. For example, people make investment on precious geological relics and monuments, and they focus mainly on the value of the culture rather than the return of economic benefits.

\section{B. Approaches for Geological Cultural Resources Exploitation}

To exploit geological cultural resources is the process of transform geological resources into geological capital. There are some basic steps for exploitation of geological cultural resources. First and foremost, step is to take scientific resources evaluation with a multi-dimensional evaluation model including economic, social, cultural and ecological level so as to give a comprehensive analysis for the market prospects and value. In this procedure, Delphy expert method and multi-level gray comprehensive evaluation method can be adopted. Second, we should integrate geological cultural recourses, make spatial layout and industrial development advantages analysis, and transform into geological cultural products with market value. Third, define the property ownership of geological cultural products, and transform into geological cultural assets in the market. Last but also important, create economic benefits through financial docking with financial instrument and gradually form related industries, industry group and then industry chain. The basic paths above shed light on in-depth exploitation of geological cultural resources and guide the whole process.

Like exploitation of other resources, geological resources need to be integrated and shared, and develop diverse products and services with market value. Geological parks are typical example. National geological park has both tourism function and scientific function, which can be used for science popularization and research base, films and TV location, and tourism sites with leisure, rehabilitation, adventure and extreme sports facilities. The development of national geological park is to protect precious geological relics and ecological environment, and to popularize geological knowledge and culture. As we know, geological relics resources are a typical kind of geological cultural resources, and good examples to follow in exploitation of other geological resources. Yunnan Shilin boasts with unique karst morphological characters, with which the country and local government have integrated resources and constructed Shilin World Geological Park. Obviously, Shilin tourism has become the pillar industry in Shilin County's economy, and have positive effect on protection of geological and nation culture, traffic and urban infrastructure construction, stone forest science research and ecological and environmental protection. Also, it has stimulated development of related industries, and developed many kinds of geological 
cultural products, such as books, audio and video, software, network, collection, exhibition, and souvenirs.

Different from exploitation of other cultural resources, exploitation of geological cultural resources should be in line with protection of resources, and take priority to both material and spiritual needs of human-beings. National Park management philosophy in the United States gives us a lot of inspiration. They strive to protect the wild state of parks, because the wilderness can let the city people feel great mental contrast in nature of life, release the pressure and return to health, and also encourage them to love life and cherish the Earth. Besides, popular science tourism with geological culture is also an important industry in the United States. In Hollywood, views may have wonderful experience in traveling in space. In the hometown of dinosaurs, Jurassic Park, views may see the simulation growth scenarios of hatching, growth and life of dinosaurs. Also, there are television, books, CDs, toys, games, movies and various products with dinosaurs as the theme, which booms a series of industries, and form industry group and industry chain. Enormous economic benefits, great social and culture value, and sense of love for the Earth, are all brought by in-depth exploitation of geological cultural resources.

\section{THREE-DIMENSIONAL COMMUNICATION OF}

\section{Geological CUltural Resources}

After hundred years of accumulation, geological cultural resources have abundant potential and high resources endowment. After exploitation of geological cultural resources into geological cultural products and services with public recognition and popularity, another task is to take three-dimensional communication in the world. To realize sustainable development of geological cultural resources, and spread them widely is of great significance to the construction of ecological civilization, as well as to promote the harmonious development of the earth and human-beings, enhance the awareness of utilizing earth resources, and frame new culture coordination indicating development of population, resources and environment.

\section{A. Public-Oriented Communication}

Public is the focus for development of geological cultural resources. With increases of demands of public, transmission and communication of geosciences culture knowledge becomes more and more prominent. We should popularize knowledge in a comprehensive and multi-level way, to popularize policy laws and regulations, actively promote materialist world outlook and the values of the harmonious development between the Earth and human-beings. We should strengthen the study of cultural resources development and create more products and services accessible to the public, and provide opportunity for the public to know more about geosciences culture. Schools should strengthen the construction of earth science courses. Museums and exhibition should popularize earth sciences knowledge in the whole society, in order to enhance the consciousness and initiative of human to protect the earth.

\section{B. Using a Variety of Communication Means}

Communication of geological cultural resources should rely on modern mass media. We should create the idea and transmit the content, by using of communication means like internet, phones, books, movie and exhibition, so as to popularize the depth and width of geological culture products and services, eventually to enhance learning effectiveness and the popularity of geological culture.

\section{International Communication}

Earth science is a global science, and geological culture is the world's culture. Geological cultural industry is international industry without boundaries, making the study of geological cultural resources a global topic with strong competition opportunity and broad market prospects. To strengthen the construction of geological culture, we should develop products and services with national characteristics and put them into international market. On the other hand, communication of geological culture should be strengthened and merged with international culture.

\section{REFERENCES}

[1] Mazzanti M. Cultural Heritage as Multi-dimensional, Multi-value and Multi--attribute Economic Good: Toward a New Frame work for Economic Analysis and Valuation [J]. Journal of Social Economics, vol. 31, pp. 529-558, 2003.

[2] Silvia Peppoloni , Ethical and cultural value of the Earth sciences Interview with Prof. Giulio Giorello [J].Annals of Geophysics, vol.3, pp.55-58, 2012.

[3] Andy S, Choi Brent, Franco Papandrea, et.al. Economic Valuation of Cultural Heritage Sites: A Choice Modeling Approach [J]. Tourism Management, vol. 4, pp.1 - 8, 2009.

[4] Zhang Wei, Promoting the Sustainable Development of Geoparks[C]. Geological Publishing House, pp. 218-222, 2009,

[5] Yichun Duan, Development of the culture of learning, promoting the harmony between human and nature [J]. Resources Industry, vol. 6, pp.47-48, 2004

[6] Dianhua Wang. The integration of humanistic spirit into the earth science education [J]. China Geology Education, vol. 2, pp. 8-10, 2003

[7] Huang Juan, Ecological civilization and science culture industry development analysis [J]. Study and Practice, vol. 10, pp. 114-119, 2013

[8] Yichun Duan, Ping Chen, The advantages and proposals of developing earth science culture industry [J]. Resources Industry, vol. 2, pp.27-30, 2007.

[9] Huang Lei, Ma Boyong. Issues and policy suggestions of geological cultural industry. [J]. Resources and Industries, vol. 2, pp.81-85, 2012.

[10] HUANG Juan., Discussion on the development of new culture of geosciences in view of ecological civilization[J].Natural Resource Economics of China, vol. 12, pp.30-33, 2012. 